\title{
Chapter 6 \\ Anticipating and Preparing \\ for the Future-One Example \\ from Higher Education: The Singapore \\ Management University (SMU) \\ Experience
}

\author{
Annie Koh
}

Today's students and graduates are facing an exciting future filled with many varied possibilities and options. As such, it has become imperative to prepare our next generation of talent with future skills for future jobs to meet the challenges of Industry 4.0. Therefore, institutions of higher learning have to be agile, bold, and collaborative in curating new and innovative programs. One approach is to cocreate the curriculum with industry to help their students stay relevant.

In fact, universities have to view themselves as strategic assets of the country to build impact. It is no longer business as usual for institutions of higher learning, wherein their mainstay activities are centered only around academic research and delivery of courses. Rather, universities should play the role of being academic entrepreneurs working closely with industry to create not just a one-size-fits-all pool of talent. Today's employers demand that the future workforce be equipped with a mix of hard and soft skills, as well as deep knowledge and flexibility, to take on multifunctional roles in their organizations.

In the past 20 years, we were increasingly aware of such challenges faced by companies and have experimented at Singapore Management University (SMU) with different initiatives and innovative programs to stay relevant. I am very honored to share some of the learning-focusing on the three Ts-Talent, Technology, and Trust working in public-private partnerships with government and industry.

\footnotetext{
A. Koh $(\bowtie)$

Vice-President of Business Development, Professor of Finance (Practice), and Academic Director of Business Families Institute and International Trading Institute, Singapore Management University, Singapore, Singapore

e-mail: anniekoh@smu.edu.sg
} 


\section{Talent Pipeline to Prepare for the Future}

Universities have to be mindful that a key purpose of education is to ensure that new generations of human capital are equipped with relevant skills and knowledge to create value for the country. As such, universities need to closely monitor the pulse of industry and develop programs to align with industry's needs. A university existing in an ivory tower will not be in a good position to anticipate and prepare its students for emerging skills and jobs.

Although SMU is a fairly young institution, set up in the year 2000, it has established itself as a leading university in Asia. This was achieved in no short measure by taking a different approach when it came to educating our undergraduate students.

Among the many differentiating factors is a program known as SMU-X, wherein the university partners with the public, private, and nongovernment sectors to provide opportunities for students to work on real-world challenges faced by the partnering organizations. Mentored by our faculty and industry experts, deep learning is developed as the students put into practice the knowledge acquired in class. This practical approach to learning also provides opportunities to develop skills such as critical thinking, teamwork, and cross-discipline collaboration that are typically difficult to cultivate in a classroom environment. SMU-X courses also allow our faculty to be closely connected with the industry.

Another example is the International Trading Institute (ITI@SMU), which was established in 2008 as a unique public-private-university partnership. It was the first of its kind in the world, set up as a direct response to the call from the commodities trading industry for a pipeline of home-grown trading talent to ensure the sustainability of Singapore as a global trading hub. As illustrated in Figure 6.1, trade is critical to Singapore's growth, accounting for $12 \%$ of our gross domestic product, and a quarter of a million jobs are related to trading and trading-related companies.

Singapore was and still is the overseas Asian headquarters of leading trading companies in need of specialized human capital to grow their businesses and thrive internationally. In 2008, with the support of 13 industry partners (the number of which has grown to 40 today) and Enterprise Singapore (ESG; the government agency in charge of trade and internationalization), SMU undergraduates from the finance major were introduced to the International Trading Track (ITT). In 2013, our economics majors were introduced to the Maritime Economics Track (MET) with support from another government agency, the Maritime and Port Authority of Singapore (MPA), and a group of maritime and shipping companies. Resulting from industry feedback, the MET was revamped in 2019 to become the Maritime Business \& Operations Track (MBOT) which shifts the curriculum focus from Economics to Operations Management (See Figure 6.2). To date, ITI@SMU has nurtured at least 400 students through the ITT, MET, and MBOT of whom $70 \%$ have chosen to enter related sectors upon graduation. Recurring feedback received from the sponsoring industry partners is that students graduating from these programs have a shorter learning curve and are almost job and skill ready from day one. 


\section{GATEWAYTO TRADE AND INVESTMENTS}

Singapore has a vibrant trading community...

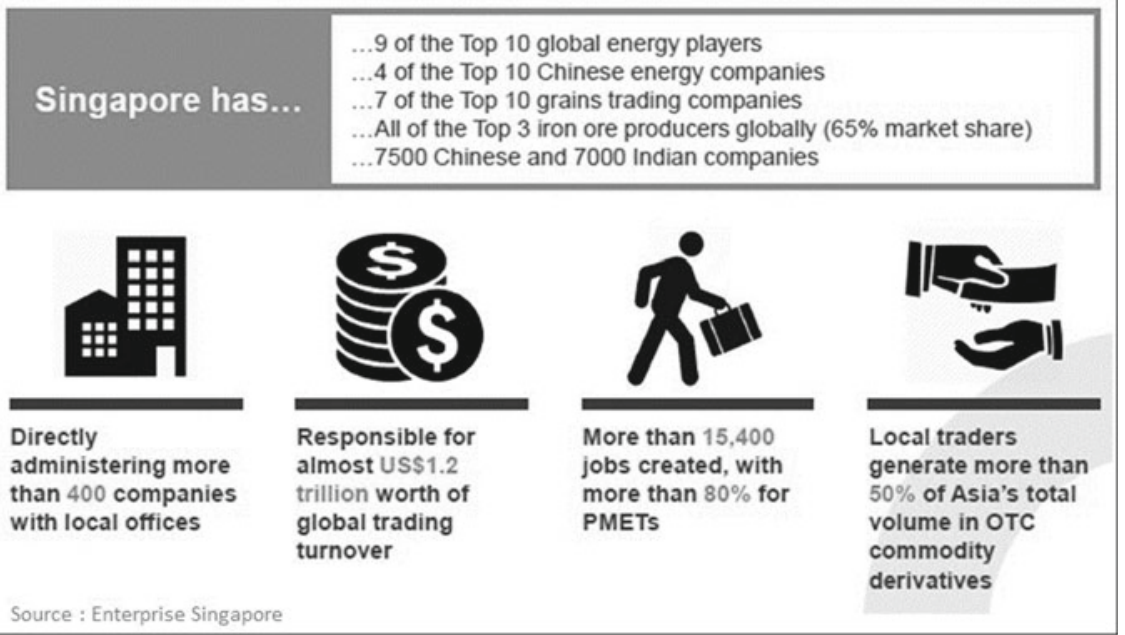

Figure 6.1 Importance of trade to Singapore's economy

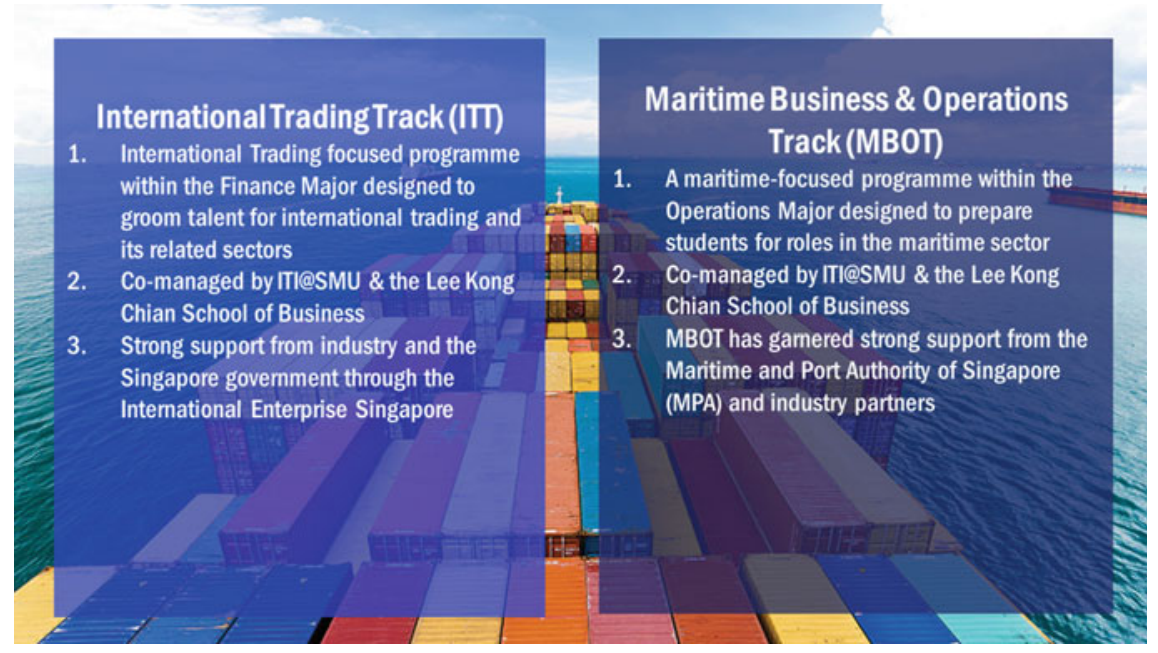

Figure 6.2 Undergraduate tracks (ITT \& MBOT) illustrating Public-Private-University partnerships 
These two programs did not consist of just a set of "for-credit" courses. Even in 2008, the university was quick to realize that, given the dynamic and demanding nature of the trading and maritime sectors, adopting a traditional structure towards the development of job-ready talent would not suffice, and a more holistic approach would have to be implemented.

Consequently, ITI@SMU introduced a number of innovative "firsts" that enabled us to attain the objective of job-ready talent. The curriculum included noncredit classes taught by industry professionals, who were able to bring their extensive work experiences into the classroom. Rich experiential learning opportunities were also provided through local site visits and overseas industry study missions wherein different cohorts of students had the opportunity to visit the world's largest refinery in Jamnagar, India; coffee plantations and processing facilities in Da Lat, Viet Nam; and oil storage facilities in Fujairah, United Arab Emirates, just to name a few. These were augmented by internships with leading trading and maritime giants such as Shell, ABN AMRO, Vitol, Trafigura, Louis Dreyfus, Maersk, Norden, and Klaveness, which provided an invaluable learning experience to prepare students for their future careers. That is why we strongly believe in having public-private-university partnerships to make work come alive.

\section{Technology—Disruptor and Enabler}

With Industry 4.0, the world is in need of critical skills in the area of digitalization, the demand for which traditional universities are finding it a challenge to keep up with. At the same time, many mid-career professionals are being laid off as their jobs are being replaced by automation and digital enhancements. These mid-career professionals are well educated, with many years of useful work-life ahead. Their jobs are being displaced but not the skills- they need new skill enhancements to work in new job roles in growth sectors.

This is where ITI@SMU stepped in once again as a strategic asset of the country to transform the wholesale trade sector with support from the government and industry partners. We went into the continuing education and training (CET) space and offered the International Trading Professional Conversion Program (PCP) to help mid-career professionals, managers, and executives (PMEs) switch career paths into wholesale trading. This is a "place and train" program made possible through the collaboration of two government agencies-Enterprise Singapore (ESG), encouraging trading firms to employ mid-career switchers, and Workforce Singapore (WSG), granting both salary and training support to the employers for helping PMEs with their career conversion journeys.

The lessons learned from running the PCP have led us to realize that digitalization is affecting all industries, and both the current and the future workforce have to be equipped with the appropriate digital skills going forward.

In addition, the existing trading and maritime undergraduate programs will be revamped and refreshed with new noncredit offerings to include courses such as data 
analytics, blockchain, and artificial intelligence applications as well as lean business processes to enhance the skills needed to help our students create value in their future jobs. Learning has indeed come full circle, with CET innovations enhancing the PreEmployment Training (PET) programs. Even our colleagues at ITI@ SMU need to retool to prepare our students for changes in skills and future jobs.

\section{Trust-The Way Forward}

The various initiatives highlighted above would never have taken place without the strong level of trust established among the various stakeholders. New technology and digital solutions would never have been adopted if there were no trust in enhancing value for end-users and employees. Partnerships among industry, government, and society would not have succeeded if "Purpose" and "People" were not at the center of the various conversion programs or new university partnership programs.

In fact, a key characteristic of the digital age will be the acceleration of globalization, as technological advances will result in the erosion of traditional boundaries. We are already witnessing the rise of e-connected platforms serviced by tech giants such as Ali Baba and Amazon that have facilitated global connectivity in trade. The internationalization of businesses and global supply chains will be a common feature as world geographical boundaries and distance, which used to restrict global trade, disappear.

Consequently, there will be a high demand for skills training that enables employees to help their companies on their internationalization journey. Adopting the right mindset towards internationalization and the acquisition of skills such as relationship building, cultural sensitivity, and international project management will be as important as understanding the technological intricacies of data analytics and how blockchain works to make supply chains sustainable.

Therefore, the way forward for both our undergraduates and professionals looking at retooling for a brave new connected world requires ITI@ SMU to add trust-building and internationalization skills into the programs to help our companies build partnerships beyond the home base. In the age where dominance of technology seems to be at the heart of so many business transactions, it is important to remember that human relationships are still at play when it comes to building cross-border partnerships and networks. Therefore, anticipating and preparing for emerging skills and jobs also require that we spend time building trust and have standards and governance in place to share data across the trade value chain. The university will be adopting these new projects in our core curriculum over the next lap, with emphasis on competencies, communities, and civilizations. Such exciting times ahead as we continue to build trust through talent and technology! 


\section{Conclusion}

The ever-changing world will require companies and individuals to adopt a flexible and nimble approach when it comes to learning. As a society, we cannot stick to the same learning format. Curricula and programs will have to be regularly refreshed and kept up to date to meet demands for new skills. As institutions of higher learning, we have a responsibility to society to be responsive to industry trends and to work closely with industry to develop human capital at all levels to meet the job needs of the future. Both innovative learning and impactful programs are needed to prepare our students and lifelong learners with the necessary competitive advantage for the future workplace. We owe it to society for the trust they have placed in education providers.

Link to the presentation material: https://events.development.asia/materials/201 71212/singapore-management-university.

The views expressed in this Chapter are those of the authors and do not necessarily reflect the views and policies of the Asian Development Bank (ADB) or its Board of Governors or the governments they represent.

ADB does not guarantee the accuracy of the data included in this Chapter and accepts no responsibility for any consequence of their use. The mention of specific companies or products of manufacturers does not imply that they are endorsed or recommended by ADB in preference to others of a similar nature that are not mentioned.

By making any designation of or reference to a particular territory or geographic area, or by using the term "country" in this Chapter, ADB does not intend to make any judgments as to the legal or other status of any territory or area.

This work is available under the Creative Commons Attribution 3.0 IGO license (CC BY 3.0 IGO) https://creativecommons.org/licenses/by/3.0/igo/. By using the content of this Chapter, you agree to be bound by the terms of this license. For attribution, translations, adaptations, and permissions, please read the provisions and terms of use at https://www.adb.org/terms-use\#openac cess.

This CC license does not apply to non-ADB copyright materials in this Chapter. If the material is attributed to another source, please contact the copyright owner or publisher of that source for permission to reproduce it. ADB cannot be held liable for any claims that arise as a result of your use of the material.

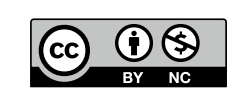

